\title{
Non-neutralizing antibodies and vaccine-induced protection
} Thorsten Demberg ${ }^{1}$, Ruth H Florese1, V Raul Gomez-Roman ${ }^{1}$, Kay Larsen², Koen KA Van Rompay ${ }^{3}$, Marta L Marthas ${ }^{3}$, David Venzon ${ }^{4}$, VS Kalyanaraman ${ }^{5}$, Ranajit Pal ${ }^{5}$, Susan W Barnett ${ }^{6}$, Aurelio Cafaro ${ }^{7}$, Barbara Ensoli ${ }^{7}$ and Marjiorie Robert-Guroff*1

\author{
Address: ${ }^{1}$ Vaccine Branch, NCI, NIH, Bethesda, Maryland 20892, USA, ${ }^{2}$ Washington National Primate Research Center, Seattle, Washington \\ 98195, USA, ${ }^{3}$ California National Primate Research Center, Davis, California 95616, USA, ${ }^{4}$ Biostatistics and Data Management Section, NCI, NIH, \\ Bethesda, Maryland 20892, USA, ${ }^{5}$ Advanced BioScience Laboratories, Inc., Kensington, Maryland 20895, USA, ${ }^{6}$ Novartis Vaccines, Emeryville, CA \\ 94608, USA and ${ }^{7}$ National AIDS Center, Istituto Superiore di Sanita, Rome, Italy \\ * Corresponding author
}

from 2006 International Meeting of The Institute of Human Virology

Baltimore, USA. 17-2I November, 2006

Published: 2 I December 2006

Retrovirology 2006, 3(SuppI I):S26 doi:I0.II86/I742-4690-3-SI-S26

(C) 2006 Demberg et al; licensee BioMed Central Ltd.

Neutralizing antibody is critical for sterilizing immunity, but recent data suggest binding antibodies may contribute to protection. A replicating Ad-HIVenv prime/Env protein boost regimen induced potent antibodies with broad antibody-dependent cellular cytotoxic activity (ADCC) across HIV clades. A multigenic Ad-SIV prime/Env subunit boost regimen elicited strong protection in rhesus macaques against SIVmac251. Significant reduction in acute viremia was correlated with non-neutralizing, ADCC-mediating anti-Env antibodies. Further, compared to multigenic vaccines, an Ad-HIVtat+Ad-HIVenv prime/Tat and Env protein boost regimen elicited significantly enhanced protection against SHIV89.6P associated with Tat and Env binding antibodies. Passive transfer of ADCC-mediating IgG has not protected neonatal macaques against oral SIV challenge. But a high challenge dose, limited IgG, and poorly functional or insufficient neonatal NK effector cells may have precluded protection. In future, other challenge routes will be studied in juvenile macaques using more ADCC-mediating IgG. 